\title{
一类一阶微分差分方程周期解的存在性
}

本文研究如下一类一阶微分差分方程

$$
\frac{d x(t)}{d t}--f[x(t), x(t-1)]
$$

的周期解的存在性, 所得的结果推广了 Kaplan 和. Yorke (参见 J. Math. Anal. Appl., 48(1974)，317-324) 的结果. 我们 总假定 $f(x, y)$ 满足如下的条件:

(i) $f(x, y)$ 在 $R^{2}$ 上连续;

(ii) $F(x, y)=\left[\begin{array}{r}-f(x, y) \\ f(y, x)\end{array}\right]$ 在 $R^{\prime}$ 上满 足局部的李普希茨条件.

\section{定理 设}

i. $f(x,-y)--f(x, y), f(-x, y)-$ $f(x, y)$, 且当 $y \neq 0$ 时, $y f(x, y)>0$;

ii. 存在 $b>0$, 使当 $x \geqslant 0, y \geqslant b$ 时有

$$
g(x, y)-\frac{f(y, x)}{f(x, y)} \leqslant \varphi(x) \phi(y),
$$

这里 $\varphi(x), \phi(y)$ 分别在 $x \geqslant 0$ 及 $y \geqslant b$ 上 是连续函数,

$$
\begin{aligned}
& \psi(y)>0 \quad(y \geqslant b), \\
& \int^{+\infty} \frac{1}{\psi(y)} d y-+\infty ;
\end{aligned}
$$

iii. $\lim _{x^{2}+y^{2} \rightarrow 0} \frac{x f(y, x)+y f(x, y)}{x^{2}+y^{2}}=\alpha \geqslant 0$, $\lim _{x^{\alpha}+y^{\prime \rightarrow+\infty}} \frac{x f(y, x)+y f(x, y)}{x^{2}+y^{2}}=\beta \geqslant 0$,

且有 $\alpha<\pi / 2<\beta$ 或 $\beta<\pi / 2<\alpha$, 则(1)式
存在周期为 4 的振动周期解.

由定理推得 Kaplan 和 Yorke 的结果. 推论设 $f(x)$ 为连续的奇函数， $x f(x)>0(x \neq 0), \int^{+\infty} f(x) d x-+\infty$, 又 设 $\alpha-\lim _{x \rightarrow 0}[f(x) / x], \beta-\lim _{x \rightarrow+\infty}[f(x) / x], \alpha<$ $\pi / 2<\beta$ 或 $\beta<\pi / 2<\alpha$, 则方程 $\frac{d x(t)}{d t}=$ $-f[x(t-1)]$ 存在周期为 4 的振动周期解. 例 1. 考虑

$$
\frac{d x(t)}{d t}--\left[a^{2}+x^{2}(t)\right] x^{2}(t-1),
$$

这里 $a>0, s-\frac{q}{p}>1, p, q$ 为正奇数, 由 定理知这个方程有周期为 4 的振动周期解. 例 2. 考虑

$$
\begin{aligned}
\frac{d x(t)}{d t}- & -a\left[1+x^{2}(t)+x^{2}(t-1)\right] \\
& \cdot x(t-1),
\end{aligned}
$$

这里 $0<a<\frac{\pi}{2}$, 由定理知方程有周期为 4 的振动周期解. 事实上, 比如当 $a=\frac{\pi}{4}$ 时, 可直接验证 $x(t)-\sin \frac{\pi t}{2}$ 就是方程的一个 周期为 4 的振动周期解，这与由定理得出的 结论是一致的。

陈永劯 (华南师范大学数学系,广州) 